\title{
Retinal Axon Divergence in the Optic Chiasm: Dynamics of Growth Cone Behavior at the Midline
}

\author{
Pierre Godement, ${ }^{2}$ Li-Chong Wang,' and Carol A. Mason' \\ 'Departments of Pathology, and Anatomy and Cell Biology, Center for Neurobiology and Behavior, College of Physicians \\ and Surgeons, Columbia University, New York, New York 10032 and 'Institut Alfred Fessard, CNRS UPR 2212, 91198 \\ Gif-Sur-Yvette, France
}

\begin{abstract}
To study how retinal ganglion cell axons diverge in the optic chiasm, the behavior of dye-labeled fibers was monitored in real time with video microscopy in an isolated preparation of embryonic mouse brain, with a focus on embryonic day 15-16. These real-time studies have revealed the dynamics of the growth of individual retinal axons, especially the tempo of extension and growth cone behaviors during divergence in the chiasm, a model for "decision" regions in developing pathways. Within the chiasm, retinal growth cones extend by saltatory growth, consisting of bursts of rapid advance alternating with pauses in extension. During pauses, growth cone appendages remain motile, and develop asymmetries prior to a change in the axis of growth. In a zone straddling the midline, retinal fibers, irrespective of destination, display long pauses for up to several hours, making small advances and retractions with no net extension. While crossed fibers ultimately progress through the midline, uncrossed fibers from inferior temporal retina develop wide-ranging branched growth cones, and then turn back to the ipsilateral side. Turns are effected by the selective retraction or micropruning of asymmetric foci of motile activity, and by the transformation of a backward-directed filopodium into a new growth cone. The behavior of retinal axons at the midline supports the hypothesis that this locus contains cues important for retinal axon divergence. Moreover, the observations of growth cone kinetics in the chiasm elucidate which growth cone forms seen in static preparations mediate growth cone turning, and suggest a model of axon navigation in decision regions in the intact nervous system.
\end{abstract}

[Key words: retinal ganglion cell axons, growth cones, optic chiasm, midline, retinal axon divergence]

\footnotetext{
Received Nov. 19, 1993; revised May 11, 1994; accepted May 24, 1994.

We thank our colleagues Drs. Gord Fishell, Dan Goldberg, Ray Guillery, Jonathan Lustgarten, Riva Marcus, Fred Maxfield, and Michael Shelanski for their technical advice and fruitful comments on the work and the manuscript. We appreciate the help of Riva Marcus, who developed the graphics for the scheme in Figure 1, and of Rich Blazeski, for photographic expertise. This work was supported by NIH Grant 27615 (C.A.M.), and by the CNRS, Ministere de la Recherche et de la Technologie, and NATO (P.G.).

Correspondence should be addressed to Carol Mason, Department of Pathology, College of Physicians and Surgeons, Columbia University, 630 West 168 th Street, New York, NY 10032.
}

Copyright (c) 1994 Society for Neuroscience $0270-6474 / 94 / 147024-16 \$ 05.00 / 0$
A salient feature of CNS development is the ability of axonal growth cones of developing neurons to follow precise paths toward their targets. Studies of normal and experimental manipulated nervous systems suggest that growth concs respond both to widespread cues that they encounter along their pathway or in targets (e.g., Harris, 1989; Cornel and Holt, 1992), and to cues present in more restricted regions (e.g., decision regions in vertebrates; Bovolenta and Dodd, 1990; Kuwada et al., 1990) or even on single cells (e.g., guidepost cells in insects; Caudy and Bentley, 1986; Klambt et al., 1991; Garriga et al., 1993).

In the decision regions of vertebrates, growth cones of different populations of neurons converge and extend in different yet specific directions. Current concepts of the mechanisms of axon navigation in these regions are based primarily on static observations of axon trajectories and shapes of growth cones in intact nervous systems. These studies have shown that in following precise trajectories, growth cones display dramatic alterations in their forms, thought to reflect the interactions that growth cones have with cellular and molecular cues in these regions. These analyses have also led to the conclusion that the variations in growth cone form are position specific, and that complex forms are more common in decision regions than in tracts, where streamlined forms predominate (e.g., Roberts and Taylor, 1983; Tosney and Landmesser, 1985; Caudy and Bentley, 1986; Bovolenta and Mason, 1987; Nordlander, 1987; Holt, 1989; Bovolenta and Dodd, 1990; Norris and Kalil, 1990; Kim et al., 1991; Yaginuma et al., 1991; Wang et al., 1993).

Studies done in vitro have shown more directly that growth cones react in various ways as they encounter the borders between different substrates (Letourneau, 1975; Burmeister and Goldberg, 1988), or different cells (Kapfhammer and Raper, 1987; Bandtlow et al., 1990; Baird et al., 1992; Cooper and Smith, 1992). These in vitro studies have disclosed elementary aspects of growth cone behavior that have been applied to situations in vivo, for example, that complex growth cone forms in decision regions may indicate active exploration or avoidance of a complex or transitional environment by the tips of growth cones. However, only limited information on the behavior of axons in their intact environment can be inferred either from static views of growth cones or observations in tissue culture.

In the visual system of higher vertebrates, retinal ganglion cell axons from each eye diverge to the same and opposite side of the brain within the optic chiasm, a classic "decision region" (Polyak, 1957; Guillery, 1982). In the mouse, as in many mammals, fibers traversing to the same side of the brain originate exclusively in the inferior temporal retina, while fibers crossing 
the midline to the opposite side of the brain derive from the remainder of the retina, and to some extent in the inferior temporal retina (Drager, 1985; Shatz and Sretavan, 1986; Godement et al., 1987a,b; Colello and Guillery, 1990; Sretavan, 1990; Reese et al., 1991; Baker and Reese, 1993). By labeling ganglion cell axons in restricted retinal regions, thereby providing an identity to crossed and uncrossed axons, we have found that the two populations are intermixed as they enter the chiasm and travel through the lateral region until they reach the vicinity of the chiasm midline (Godement et al., 1990). At this site, ipsilateral-projecting fibers diverge from crossing fibers, by developing large, often bifurcated or multiply branched terminal endings at the border of a zone 150-200 $\mu \mathrm{m}$ proximal to the midline. These growth cones display even more complex morphologies than those described in our original study on growth cone form and position in the mouse visual system and chiasm in particular (Bovolenta and Mason, 1987). By inference from the images of curving growth cones and the sharp angle of the proximal neurite, we concluded that those branched fibers tipped with bifurcated or complex growth cones turn away from the midline back toward the ipsilateral optic tract.

These studies suggest that crossed and uncrossed retinal fiber growth cones respond differentially to their immediate environment in the optic chiasm, and that within this decision region, the midline seems to be relevant for directing growth cones of retinal fibers to the same or other side of the brain. This conclusion was also reached in recent analysis of retinal axon growth viewed in real time by Sretavan and Reichardt (1993). In other studies in our laboratory, examination of the cellular composition of the optic chiasm during ingrowth of retinal fibers has revealed a palisade of radial glia that straddles the optic chiasm midline. Since crossed and uncrossed fibers diverge with reference to this palisade (Mason et al., 1991; R. C. Marcus, R. Blazeski, P. Godement, and C. A. Mason, unpublished observations), we consider this cellular specialization a candidate cue for retinal axon divergence.

In this study, we have asked how growth cones navigate within decision regions of pathways to targets, using the retinal axonoptic chiasm system as a model. In particular, we determined the itinerary or spatiotemporal pattern of growth through the various subregions of the decision area, the behaviors displayed at any one point in the itinerary, and the forms of growth cones mediating these behaviors. To examine these aspects of the behavior of retinal ganglion cell growth cones, we imaged dyelabeled axons as they grew through the optic chiasm in a semiintact living preparation taken from mouse embryonic brain. With the real-time approach, the dynamics of growth and changes of morphology of individual growth cones can be studied as they navigate in the context of the actual pathways, in this case, as they diverge toward each side of the brain.

\section{Materials and Methods}

Dissection of retina-chiasm slab preparation. The embryos used for making preparations for video-time-lapse imaging were derived from a timed-pregnancy breeding colony of $\mathrm{C} 57 \mathrm{BL} / 6 \mathrm{~J}$ mice maintained under our direction at Columbia University. Mice were mated at night, between 6 P.M. and 9 A.M. the next day. Coupling was assumed to have occurred at midnight the day before a plug (determined in the morning) was discovered. The first day of gestation was thus considered E0.

Embryos were retrieved from pregnant mothers anesthetized with ketamine/xylazine $(50 \mathrm{mg} / \mathrm{kg}$ and $10 \mathrm{mg} / \mathrm{kg}$, respectively) and put in cold F12-DMEM medium (GIBCO). A 200-300 $\mu \mathrm{m}$ slab of ventral diencephalon, including the optic chiasm with both retinas and optic nerves attached, was dissected from the brain. This tissue was then
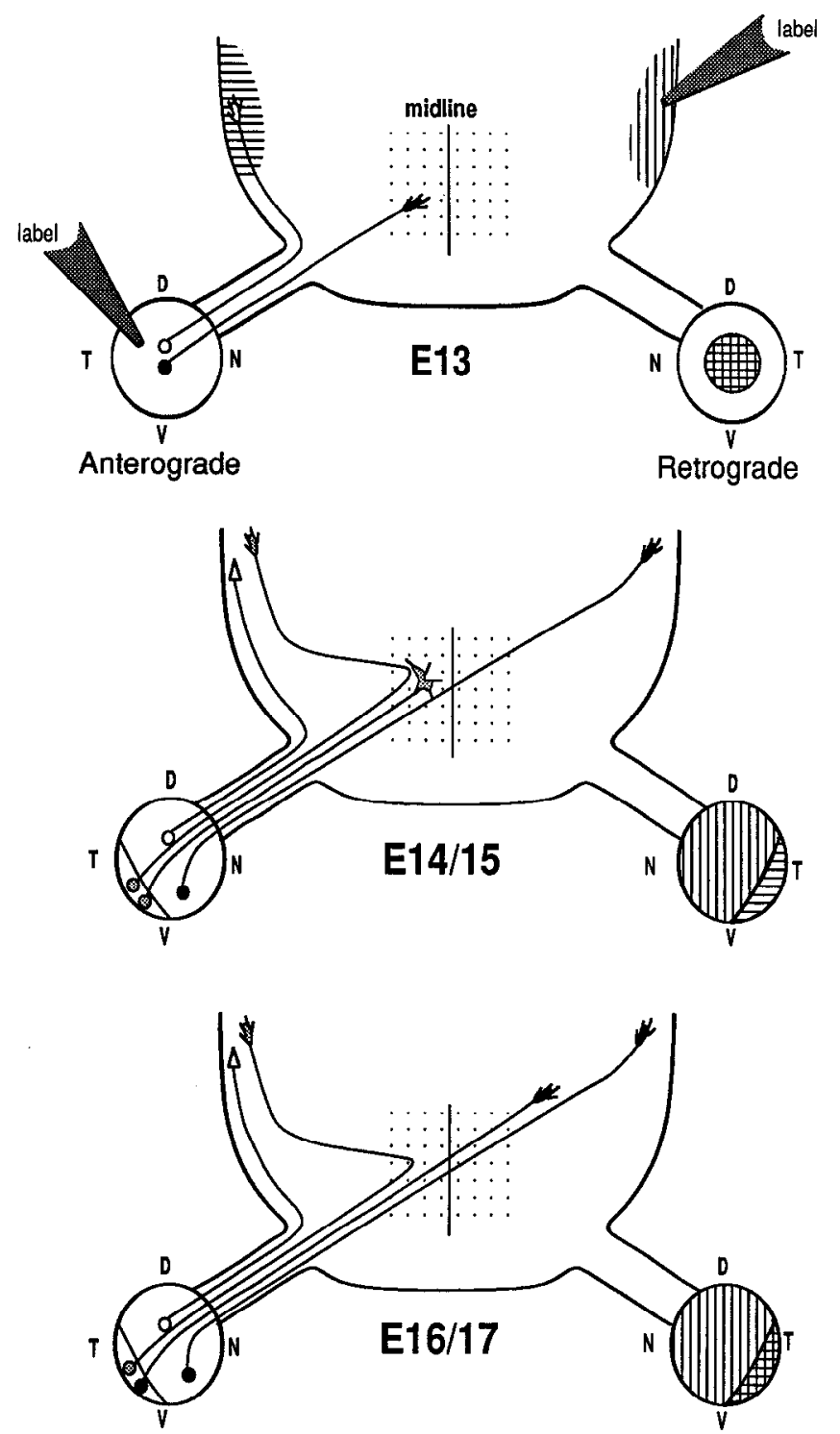

Figure 1. Schematic view of ipsi- and contralateral retinal projections at three different embryonic ages. The axons figured on the left display trajectories and general growth cone form as observed after anterograde labeling from regions depicted in the left retina. The right retina indicates retrograde labeling of retinal ganglion cells after placing DiI in the optic tract on both ipsi- (vertical lines) and contralateral (horizontal lines) sides. Key to growth cone shading: white, transient ipsilateral fibers from dorsal central retina; stippled, ipsilateral fibers from inferior temporal retina; black, crossing fibers. In the majority of preparations analyzed in the present study, dye was placed in the inferior temporal retina at E15, yielding fiber trajectories shown in the middle and bottom diagrams. At E13, uncrossed fibers arise from dorsal central retina (Godement et al., 1987a; Colello and Guillery, 1990). At E15, the bulk of the uncrossed projection arises from the inferior temporal retina (Colello and Guillery, 1990; Godement et al., 1990; Sretavan, 1990). By E16-17, a small crossed projection also arises from the inferior temporal retina (Collelo and Guillery, 1990). Throughout the period studied and into late embryonic ages, a few scattered uncrossed ganglion cells remain outside the temporal crescent (Godement et al., 1987a, 1990; Colello and Guillery, 1990; Sretavan, 1990), but are not figured here for the sake of clarity.

spread, ventral surface down, on the surface of a coverslip dish (Hatten and Francois, 1981) coated with polylysine-laminin (200 and $20 \mu \mathrm{g} / \mathrm{ml}$, respectively), such that the preparation assumed an $\mathrm{X}$ and flattened on the coverslip.

Because inferior temporal fibers in the act of turning have been ob- 

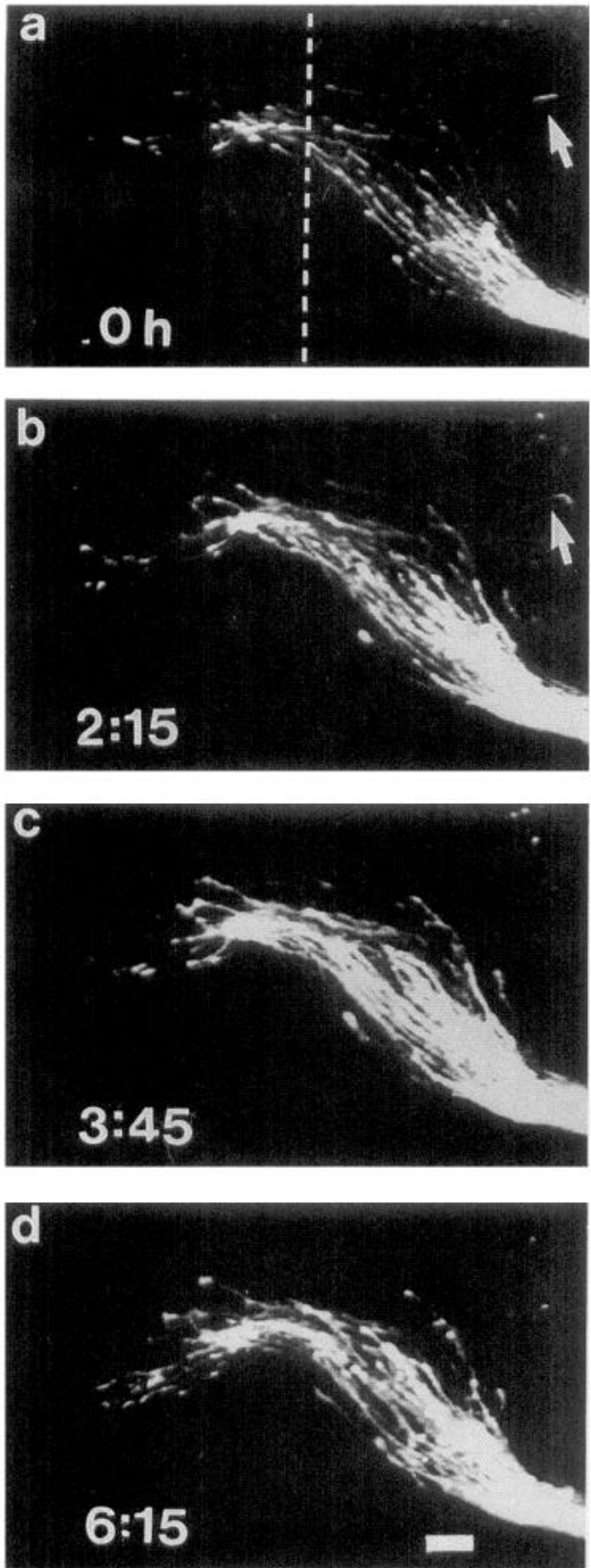

Figure 2. Low-power view of a cohort of axons crossing the midline. DiI was injected in central dorsal retina at E13.5. Recording began 8 hr later on the same day and continued for $15 \mathrm{hr}$ (time is shown in hours). This sequence extends from hour 2 to hour 8 of recording, corresponding to early E14. A large cohort of fibers sweeps toward and across the midline (vertical dashed line). Unlike the later ages studied uncrossed fibers (arrow) project directly into the ipsilateral optic tract (see Fig. 1, top diagram). This figure also demonstrates that the isolated preparations are viable for up to $36 \mathrm{hr}$, after dissection and subsequent video time-lapse microscopy. Scale bar, $50 \mu \mathrm{m}$.

served in fixed dye-labeled preparations primarily between E15 and E16 (Godement et al., 1990, Fig. 1), most embryos used for viewing these fibers in real-time were taken at E14 or at E15 and studied by video microscopy approximately $12 \mathrm{hr}$ later. With the help of a micropipette, a small crystal of DiI (1,1'-dioctadecyl-3,3,3',3'-tetramethylindocarbocyanine perchlorate; Molecular Probes) was applied near the lower temporal periphery of the retina for labeling uncrossed fibers, or elsewhere for labeling crossed fibers. E13 embryos were also used to observe earlier stages of retinal fiber growth in the optic chiasm. In these embryos, a small crystal of DiI was applied in dorsal central retina, halfway
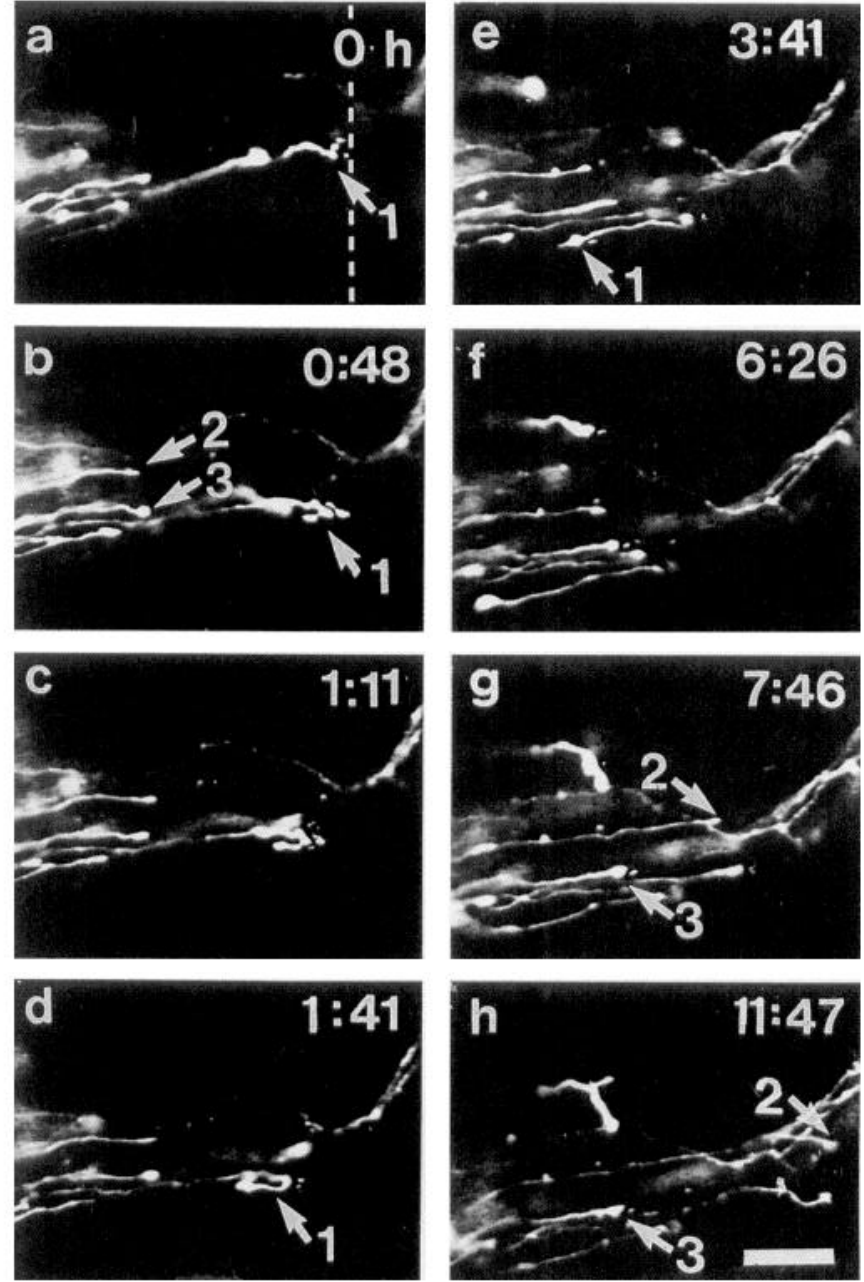

Figure 3. Low-power view of an axon turning along the midline zone, and two pausing axons, one of which will cross the midline (time shown in hours). DiI was injected into the inferior temporal retina at E15.5 and viewed the next day over a $12 \mathrm{hr}$ period. Growth cone 1 spread and turned sharply at the midline (vertical dashed line). $a$ and $b$, Spreading of the growth cone during a $40 \mathrm{~min}$ period. $c-e$, The growth cone effects the turn and the axon grows out of view $(f-h)$, in the direction of the ipsilateral optic tract. Growth cones 2 and 3 (marked in $b$ ) pause in their advance during the first $7 \mathrm{hr}$. Growth cone 2 then crosses the midline while growth cone 3 remains in the same position. In $b$, the tips of both axons are not aligned, but 2 advances relative to 3 , while in $d$ they are positioned at the same distance from the midline. In $e$, the tip of 3 has advanced relative to the tip of 2 . In $g$, the tip of 2 has extended farther and crosses the midline in $h$. The tip of 3 has retracted slightly in the $4 \mathrm{hr}$ between $g$ and $h$. Scale bar, $50 \mu \mathrm{m}$.

between the optic disk and the retinal periphery (Fig. 1). After dye application, medium was added (F12-DMEM medium with $15 \mathrm{~mm}$ HEPES buffer, $33 \mathrm{~mm}$ glucose, $0.4 \%$ methylcellulose, $10 \%$ fetal bovine serum). Six to ten such preparations were made for each experiment and kept in medium in an incubator $\left(36^{\circ} \mathrm{C}, 4 \% \mathrm{CO}_{2}\right)$ until video recordings were made. Labeling of fibers with DiI within the chiasm was satisfactory after $12 \mathrm{hr}$ of incubation, although for young embryos (E13) this time could be shortened.

Video microscopy. The optimal viewing time of axons within the chiasm was 12-36 hr after dye application, and in some cases extended to several hours thereafter (see Results). After selecting a preparation, the dish containing it was sealed with Parafilm, and placed on the stage of an epifluorescence inverted microscope (Zeiss IM 35 with a $50 \mathrm{~W}$ mercury lamp), maintained at $36^{\circ} \mathrm{C}$ with a thermostatically driven heater. Potentially damaging illumination was reduced by placing two neutral density filters $(0.9+0.5 \mathrm{ND})$ and a shutter (Uniblitz) in the light 

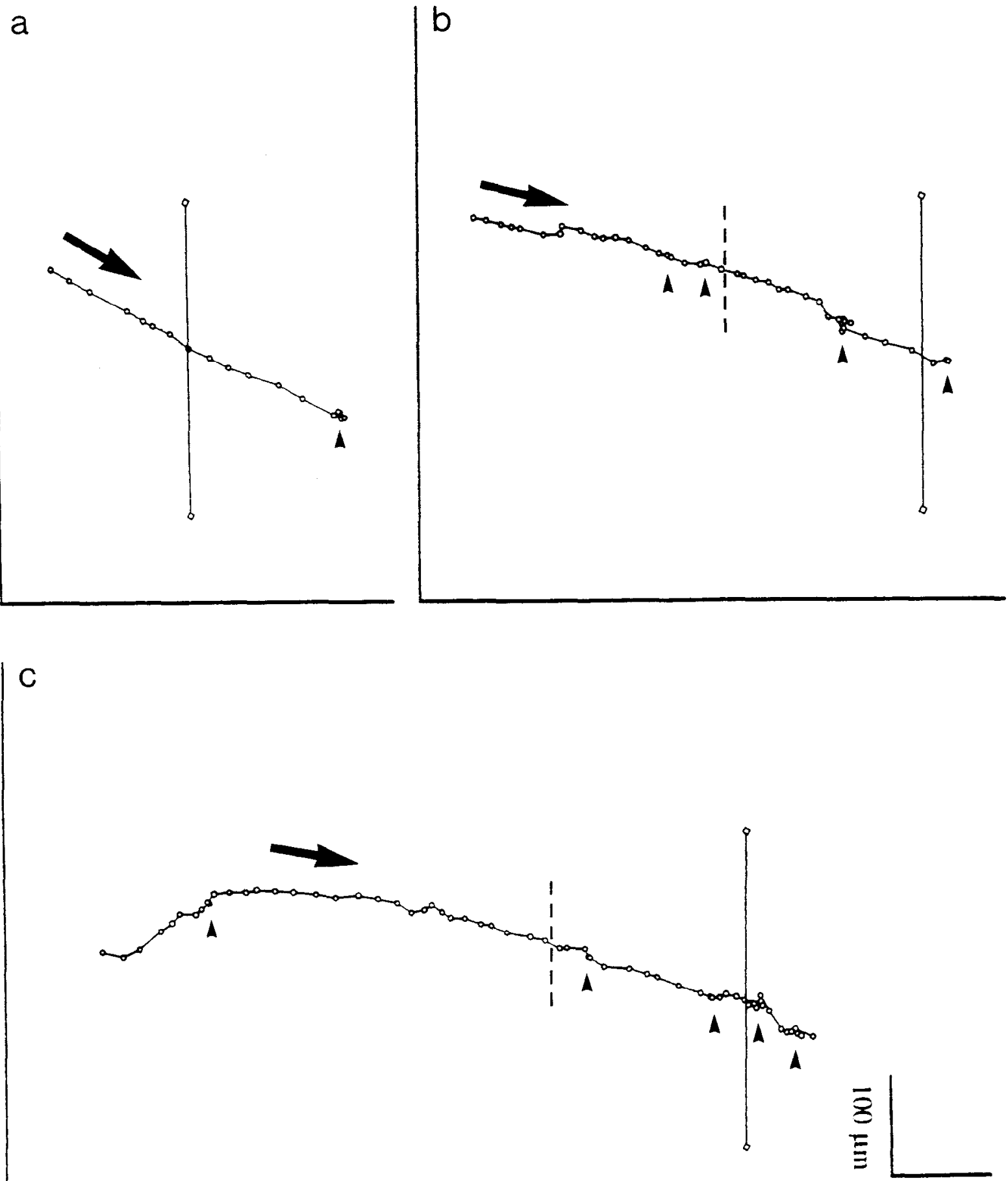

$100 \mu \mathrm{m}$

Figure 4. Plots of growth cone kinetics of three axons that cross the midline. Axons were labeled with DiI in the inferior temporal retina $(A)$ and dorsal temporal retain $(B, C)$ at E14 and viewed at E15. Each circle represents the position of the neck of the growth cone, recorded every 15 min. Growth cones moved from left to right. Pauses are evident where circles overlap or come together (arrowheads), usually where extension of the neck and tip did not occur or was less than $5 \mu$. The fibers in $b$ and $c$ display pauses prior to and at the midline (straight line), respectively. Dashed line indicates the division between lateral chiasm and the $200-\mu \mathrm{m}$-wide midline zone, which is adjacent to and proximal to the midline.

path. Images were obtained with a three-stage intensifier camera (Zeiss Venus) or Hamamatsu intensified CCD camera and recorded onto a optical disk recorder (Panasonic) after being processed by a digital image processor (IMAGE-1, Universal Imaging Corporation, West Chester, PA). The image processor also controlled the opening of the shutter. Groups of fibers were observed with lower power objectives (Nikon
$10 \times$, NA 0.5 and $20 \times$, NA 0.75 ) for up to $36 \mathrm{hr}$, with no signs of degeneration. Several frames (four or eight) were averaged and recordings were made every $15 \mathrm{~min}$ with the shutter open for $250 \mathrm{msec}$. Individual fibers and growth cones were observed at higher magnification using an oil immersion objective (Zeiss Plan Neofluar 100×, NA 1.3) for $1.5-3 \mathrm{hr}$ with the shutter opened every $2-5 \mathrm{~min}$. The focus was 
a

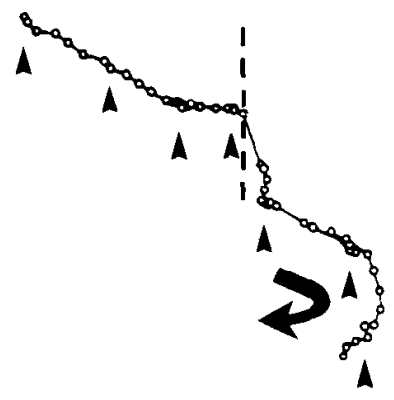

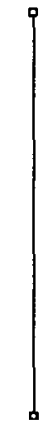

b

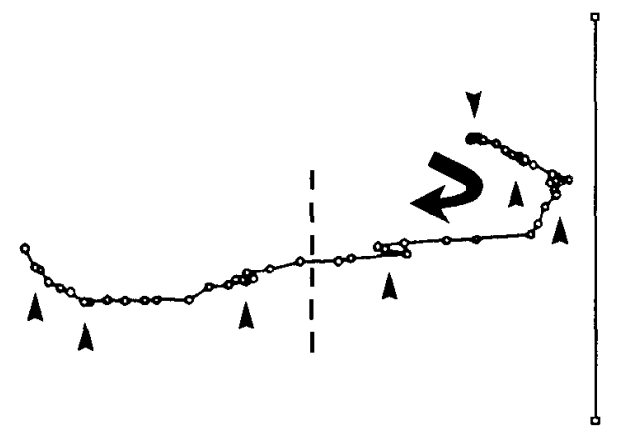

C

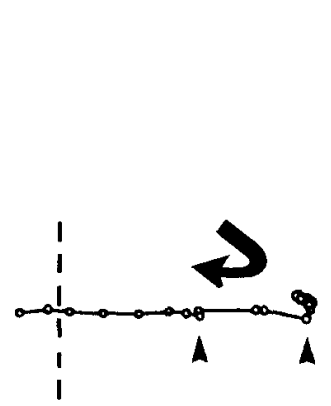

continually monitored, and changed manually if the fiber or growth cone went out of the plane of focus. At high magnification, the shutter opening was brief $(50 \mathrm{msec})$, allowing only single frames to be recorded. At the beginning and end of each recording session for each preparation, a frame was recorded with phase or bright-field at $10 \times$ and $20 \times$ magnification to view the orientation of the preparation, and to determine the position of the midline.

After a series of images was obtained from living preparations, two features of growth were quantitated with the Image-1 system. To plot the movement of each growth cone over time, each frame was displayed and a dot was placed over the neck of the growth cone (the neurite immediately behind the body of the growth cone). With the "track point function," as each frame was imaged, a list of points representing the same growth cone was generated. The list of points was converted to a plot with CA-CRICKET GRAPH III software (version 1.1). To measure the rate of growth cone advance, the distance moved over time was measured with same function and statistically analyzed. For both measures at low power, the track point function was used to mark the midline, imaging the preparation in phase at low power, and making two marks at the anterior and posterior poles of the midline; the track points were then automatically connected by a line that represented the midline.

Real-time sequences were obtained from over 40 preparations, primarily at E15-E16. Five preparations were studied at E14. The total number of time-lapse sequences made at low magnification was 82 $(10 \times)$ and $29(20 \times), 14$ at $100 \times$, and from these, the kinetics (advance/ pause cycles, and rates of growth) were computed for 64 axons. The total number of growth cones whose morphology was analyzed at high magnification was eight $(100 \times)$. The average length of recording sessions of axons at $10 \times$ or $20 \times$ was $12 \mathrm{hr}$ but in some cases extended to 36 hr. At higher power $(100 \times)$, individual axons were recorded for an average of $3 \mathrm{hr}$.

Preparations were first scanned at low power to locate fibers primarily in the midline area. Axons and growth cones were selected to be monitored if the DiI labeling was intense and if the morphology of the axon and growth cone was not beaded, a sign of degeneration. Preparations showing small numbers (10-30) of well-labeled fibers were best for plotting the movement of individual growth cones at low power. Growth cones were chosen for analysis of morphological changes at high magnification if few other fibers or growth cones were labeled in that area so that the background fluorescence would not obscure the edges of the neurite or growth cone. If the fiber tip showed no evidence of advance for more than an hour at $10 \times$ or $20 \times$, or if the growth cone showed no signs of motility for more than $30 \mathrm{~min}$ at $100 \times$, these fibers and growth cones were not included in the analysis.

To determine the changes in growth cone form, individual frames were viewed on the TV monitor. The image from each frame was then either photographed with a Nikon camera with Micronikkor lens and T-Max film $(35 \mathrm{~mm})$, or drawn by placing a sheet of acetate on the monitor, marking a fixed point, and tracing the outline of the growth cone in each frame.

\section{Results}

Axon growth in the retina-optic chiasm preparations

In the chiasm slab preparations that were incubated overnight, labeled retina fibers arrived in the chiasm in a time frame similar to that deduced from studies on the intact animal. Moreover, the pathways that retinal fibers took were consistent with observations made in sections of the intact embryo, both for earlygrowing fibers (E13-E14) and for later-growing fibers (E15-E16).

At E13, retinal fibers from the central aspects of the retina reach the optic chiasm, and most fibers cross at a restricted site along the optic chiasm midline (Godement et al., 1987b, 1990;

Figure 5. Plots of growth cone kinetics of three axons that turn away from the midline. Conventions are as in Figure 4, but retinal fibers were labeled only in inferior temporal retina. Curved arrows indicate the direction of turning. All three axons show several pauses (arrowheads) prior to turning near the midline (straight line). Dashed line indicates the division between lateral chiasm and the 200- $\mathrm{m}$-wide zone proximal to the midline. Pausing also occurred in the lateral chiasm near the border of the midline zone. 

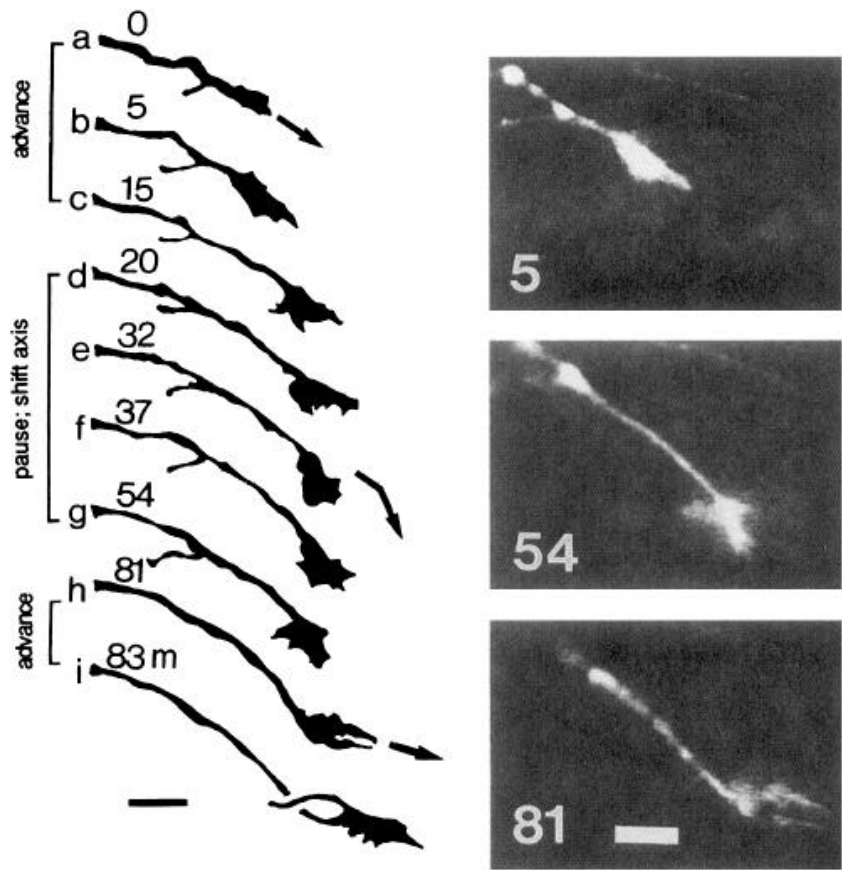

Figure 6. Growth cone advance is interrupted by pauses, during which the axis of growth shifts. The growth cone was labeled by injecting the dorsal nasal retina in the afternoon of E15, and then monitored $16 \mathrm{hr}$ later. Left panel shows the overall form of the growth cone traced from the video recordings. From $0 \mathrm{~min}$ to $15 \mathrm{~min}$ the growth cone extends $25 \mu \mathrm{m}$, and has a elongated tapered form. From $5 \mathrm{~min}$ to $54 \mathrm{~min}$, the growth cone stalled and changed shape, becoming more spread. From $54 \mathrm{~min}$ to $81 \mathrm{~min}$, a lamella points "downward." From $81 \mathrm{~min}$ to 89 min the growth cone reextends an additional $12 \mu \mathrm{m}$, in a new axis parallel to the original axis but shifted by several micrometers (arrow at $81 \mathrm{~min}$ ). Right panel shows selected photographs of growth cones photographed from the video monitor. Scale bar, $25 \mu \mathrm{m}$.

Colello and Guillery, 1990; Sretavan, 1990; Fig. 1). As shown in Figure 2, these features also developed in the preparations that we used. The sequence of growth of retinal fibers is shown in Figure 2 from a preparation in which the central dorsal retina was labeled at E13.5. At the beginning of the recording session

Figure 7. Growth cone shape changes during pauses and advance in an axon crossing the midline. Tracings of a growth cone labeled in the dorsal temporal retina at E15, and monitored $18 \mathrm{hr}$ later with a $100 \times$ objective, as it crossed the midline (see inset). The growth cone is tapered and streamlined during advance (solid arrows, e.g., from 0 to $12 \mathrm{~min}$ ) and spread and complex during a pause. During a pause from 24 to 60 min, the growth cone changes shape but neither the tip nor the neck of the growth cone advanced (dashed line). From 98 to $107 \mathrm{~min}$ the tip advanced but not the neck. From 134 to $158 \mathrm{~min}$, the neck of the growth cone moved forward but not the tip. At $191 \mathrm{~min}$ a filopodial branch (asterisk) pointing at an angle different from the previous axis of growth, established a slight shift in the direction of extension (open arrow). In comparison to ipsilaterally projecting growth cones (compare axon 2 in Fig. 3; see also Figs. 9-11), crossing growth cones never spread to the same extent, formed Y shapes, or split into multiple growth cones. Inset, Horizontal view of the chiasm, with position of the growth cone at the end of monitoring. The outlines of the growth cone and neurite were traced from the monitor on an acetate sheet at $10 \times$; the preparation, including the optic nerves (pointing upward on the figure) and chiasm, was then viewed with phase optics and their outlines traced. Straight line represents the midline. Scale bars: long bar, $25 \mu \mathrm{m}$; short bar, 100 $\mu \mathrm{m}$ for inset.
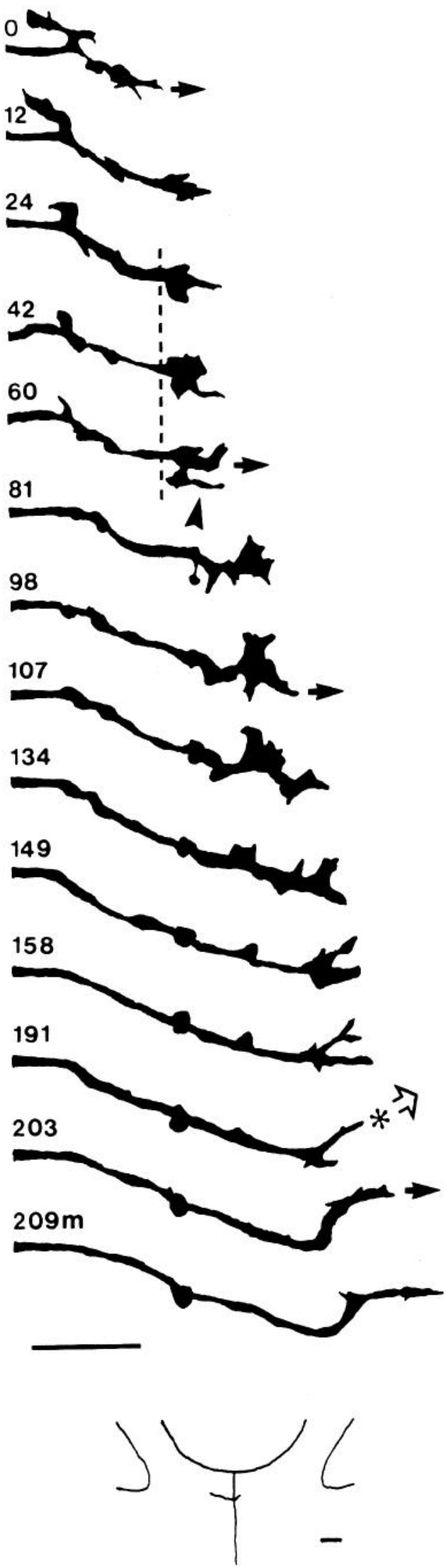

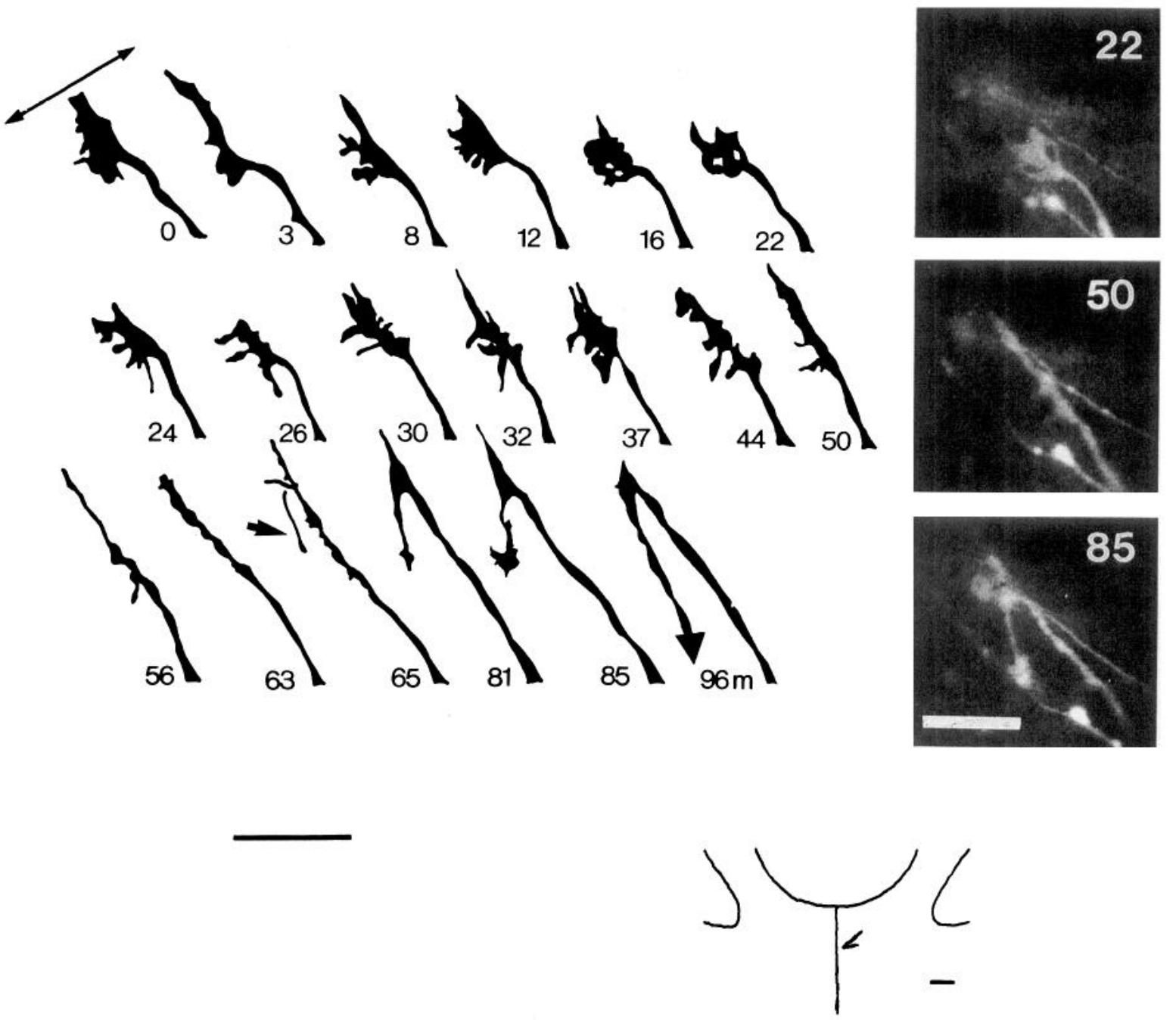

Figure 8. The steps in growth cone turning. This fiber was labeled in the inferior temporal retina at E16, and recorded $16 \mathrm{hr}$ later, with a $100 \times$ objective. After pausing at the midline (line with arrowheads), the growth cone turned back toward the ipsilateral optic tract. Recordings were made over $96 \mathrm{~min}$. Drawings are tracings from the video images. Three phases of the turning process include the following. $A$, Advance and retraction of the body of the growth cone with no net advance. Over a period of $1 \mathrm{hr}$, the growth cone was alternately spread and squat (photo at $22 \mathrm{~min}$ ), and extended as a thin spear (photo at $50 \mathrm{~min}) . \mathrm{B}$, A backward filopodium develops $(65 \mathrm{~min})$ and a new small growth cone formed at its tip $(81-$ $85 \mathrm{~min}$ ). $C$, The new growth cone rapidly extended out of view, back to the ipsilateral optic tract and off the screen. Inset is as in Figure 7 . Scale bars: long bar, $25 \mu \mathrm{m}$; short bar, $100 \mu \mathrm{m}$ for inset.

$8 \mathrm{hr}$ later, most labeled fibers were still within the optic nerve or lateral aspect of the optic chiasm. Subsequently, in the $15 \mathrm{hr}$ during which they were imaged, retinal axons approached the midline, crossed it at a restricted site, and proceeded to the other side of the midline along a pathway that matched the location of the optic tract. A few fibers did not head toward the midline, and instead turned ipsilaterally in the lateral optic chiasm (Fig. 2, arrows).

In vivo, the uncrossed projection from ganglion cells in the inferior temporal edge of the retina can first be seen in the optic chiasm in the second half of E14 (Fig. 1) (Godement et al., 1987b, 1990; Colello and Guillery, 1990; Sretavan, 1990). In preparations made from embryos aged E14 to E15 and observed 12-16 $\mathrm{hr}$ later, fibers labeled in the areas of retina giving rise to crossed fibers (dorsal temporal or nasal) arrived in the chiasm, crossed at the ventral anterior border of the chiasm, and proceeded into the contralateral optic tract along the side of the diencephalon. Very few uncrossed fibers were labeled after such injections. Uncrossed fibers were reliably labeled only when DiI was applied to the edge of the inferior temporal retina at these ages. These fibers approached the midline, then turned back to continue growing toward the ipsilateral optic tract (Fig. 3). A variable proportion of crossing fibers were also observed after inferior temporal injections at E15. These fibers may belong to the crossed component that develops from this region of the retina soon after the uncrossed component, at around E16 (Colello and Guillery, 1990; Fig. 1).

Because our objective was to examine the behaviors of the growth cones of crossed and uncrossed retinal fibers that give rise to the final retinal decussation pattern during the major phase of their divergence at the optic chiasm, we chose to document the real-time behavior of crossed and uncrossed axons growing from the retina between E14 and E16, and arising from inferior temporal retina in particular, rather than the fibers growing in the earlier period (see Sretavan and Reichardt, 1993; see also Fig. 1). 

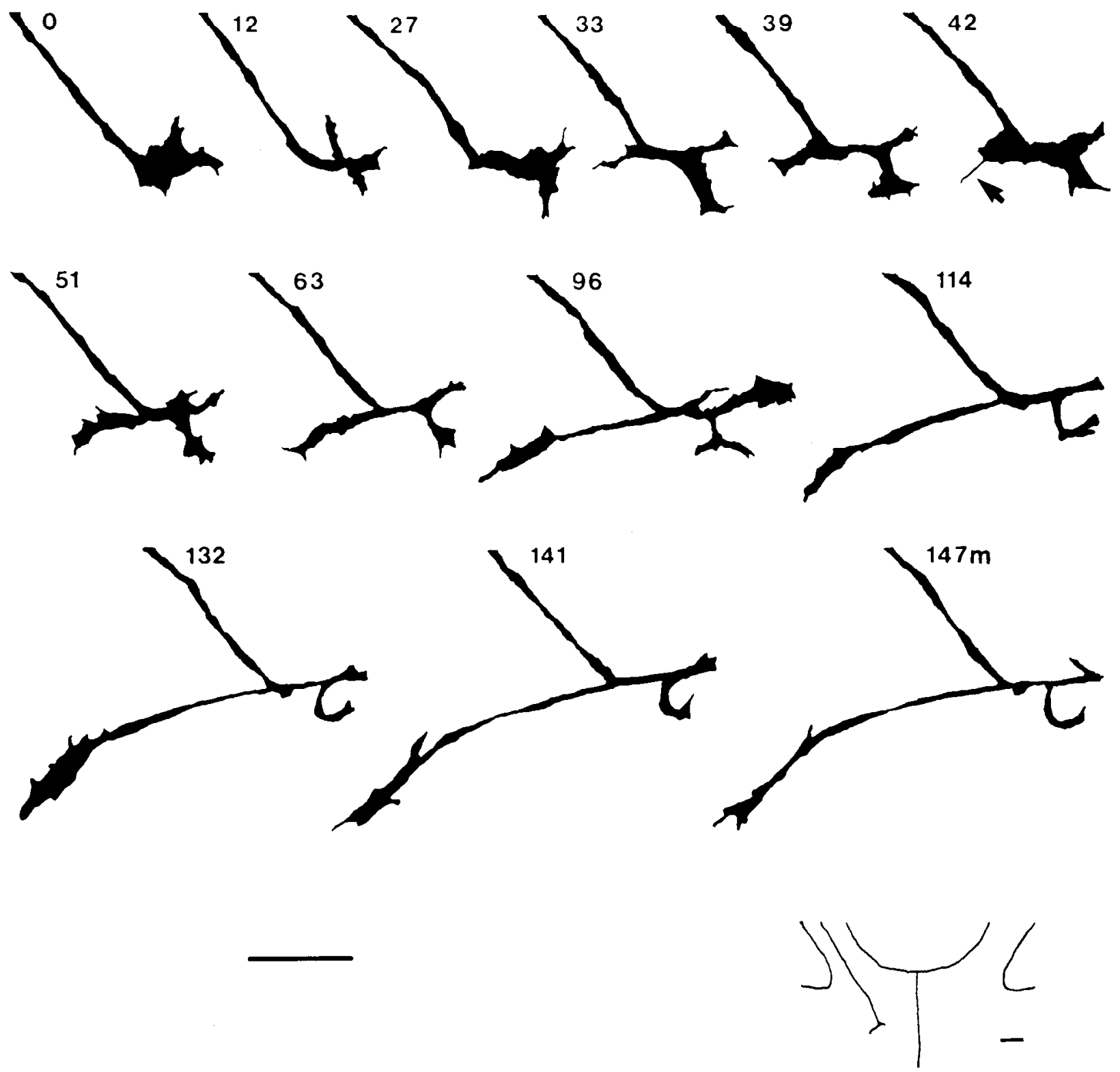

Figure 9. Growth cone turning at the midline. Injection parameters are as in Figure 8. A single growth cone developed several points of activity, and divided into a $\mathrm{T}$ shape $(12 \mathrm{~min})$, the body of the growth cone expanded and one of the $\mathrm{T}$ processes retracted, then again developed a tripartite shape $(33 \mathrm{~min}$ ). The left portion then shrunk to a fine filopodium (arrow) and then expanded again, and between 63 and $96 \mathrm{~min}$, a new growth cone developed at the tip of this portion and extended in this new axis of growth, cssentially effecting a turn. The right and downward-pointing portions subsequently condensed but their remnants remained from $114 \mathrm{~min}$ onward. Note that the shape of the advancing growth cone is tapered, as in Figure 7. Compare these images to static images of DiI-labeled axons in Figure $5 F-H$, and Figure $6 M-O$ in Godement et al. (1990). Inset is as in Figure 7. Scale bars: long bar, $25 \mu \mathrm{m}$; short bar, $100 \mu \mathrm{m}$ for inset.

\section{Kinetics of growth}

A striking feature of the kinetics of retinal axon growth within the chiasm at E15-E16 was the saltatory nature of the progression of each growth cone, discernable at low power when large numbers of fibers were in view. This was apparent at low (Fig. 3 ) and at high magnification (Figs. 6-10), both in the actual video time-lapse recordings (Fig. 3) and when the course of axons was plotted (Figs. 4,5 ). In the plots tracking growth at low magnification $(10 \times$ or $20 \times)$, circles marked the position of the neck of the growth cone (the neurite immediately behind the body of the growth cone) every $15 \mathrm{~min}$. Pauses were defincd when the neck of the growth cone did not advance forward at all or moved less than $5 \mu \mathrm{M}$, visualized on the plot when the circles came together or overlapped two or more times (arrowheads in Figs. 4, 5).

The plots in Figures 4 and 5 demonstrate the tempo of growth in the chiasm. Although pauses in advance occurred in the lateral chiasmatic regions (the region $150-200 \mu \mathrm{m}$ adjacent and lateral to the midline region), they were particularly prominent near in the midline zone (150-200 $\mu \mathrm{m}$ adjacent to the midline), irrespective of the crossed or uncrossed destination of fibers (Figs. 4, 5; Table 1). Both the frequency and duration of the pauses was greater in the midline region, particularly evident where two or more circles overlap or "pile up" and resulting in a blurring of the circle outlines (e.g., at the beginning of the plot 

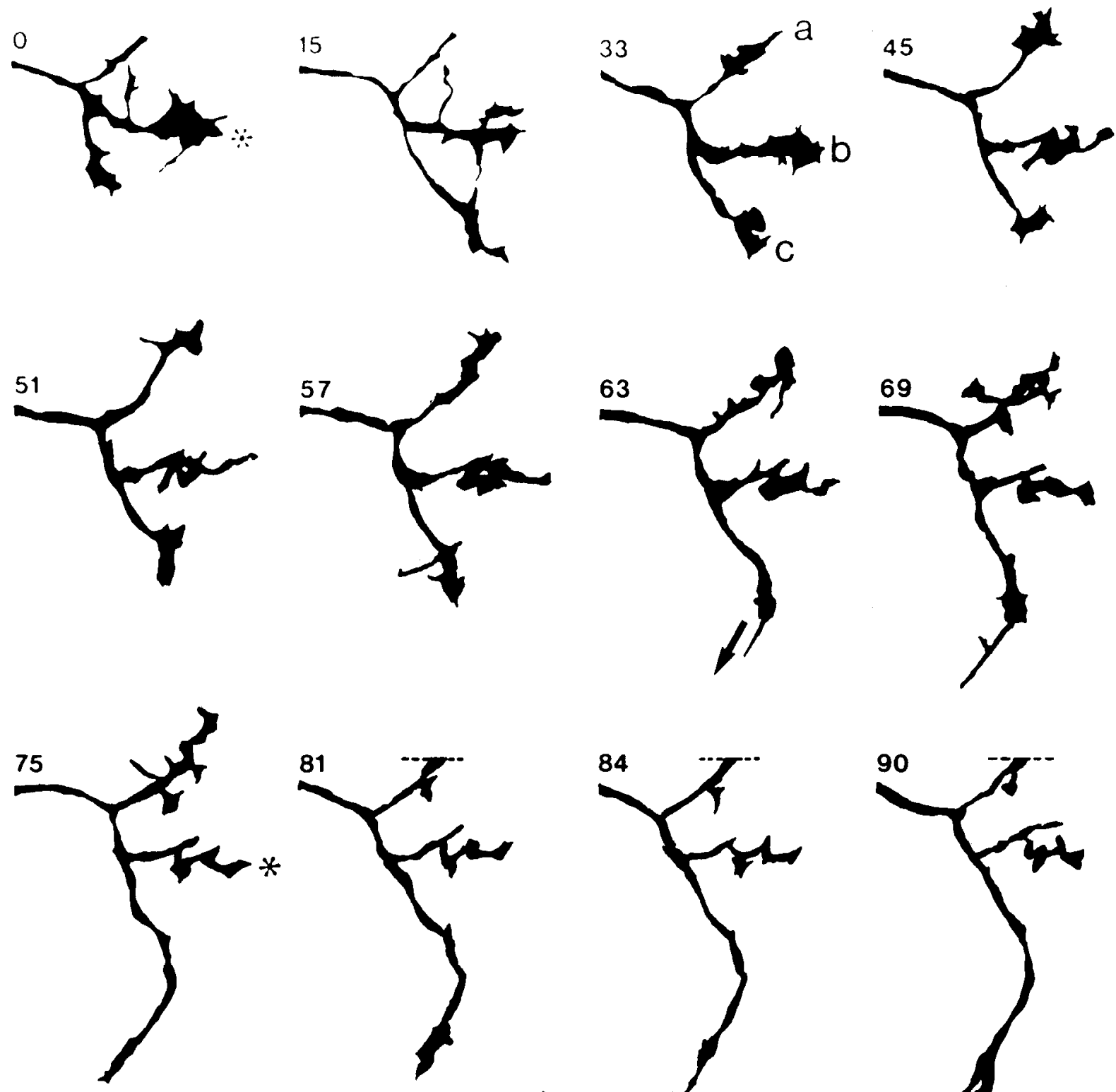

136
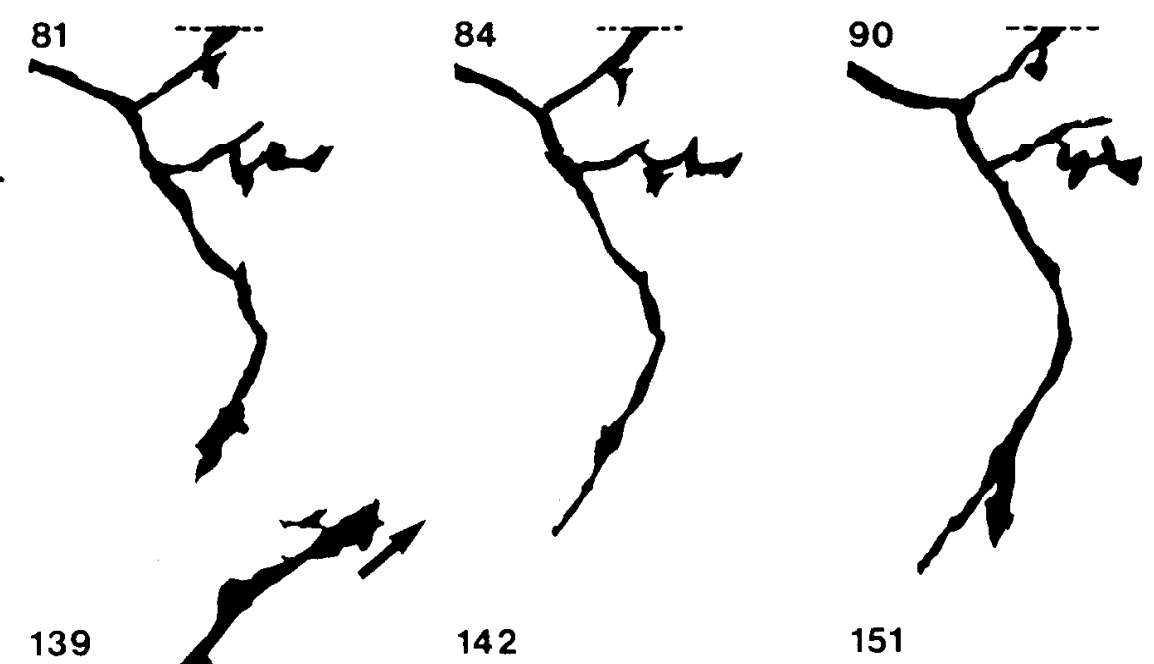

142
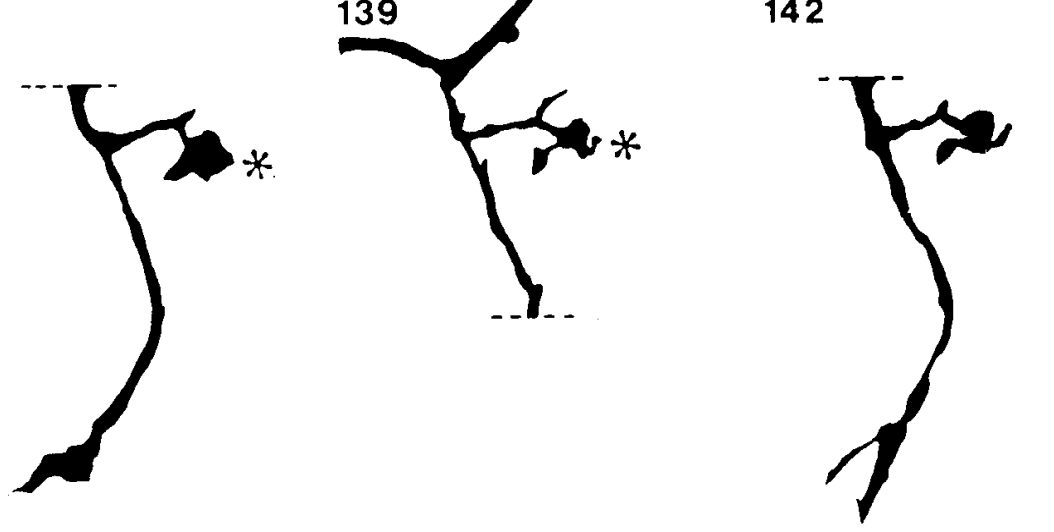

151

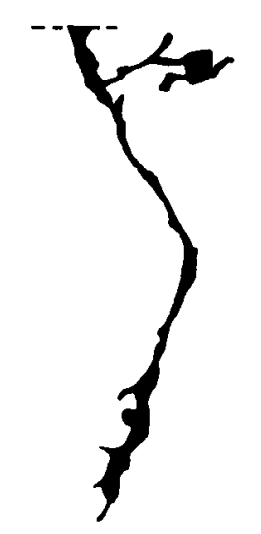


157

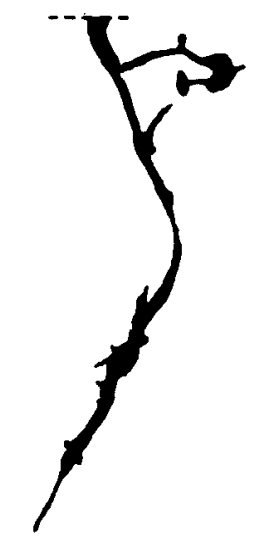

175

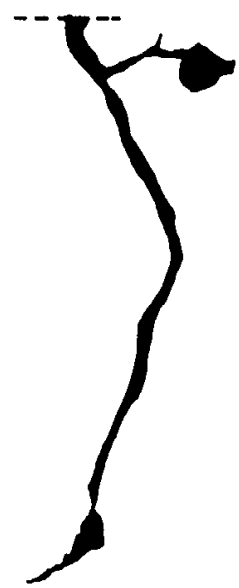

160

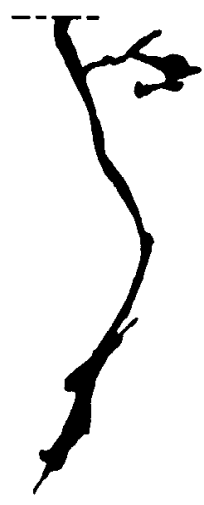

$178 \mathrm{~m}$

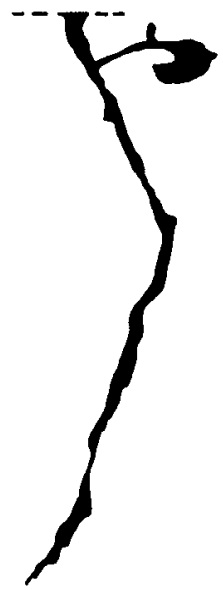

166

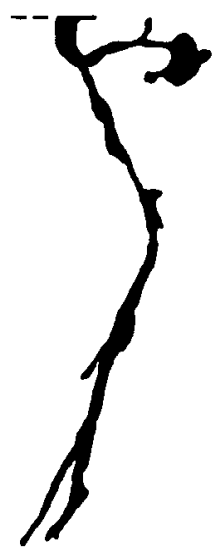

169

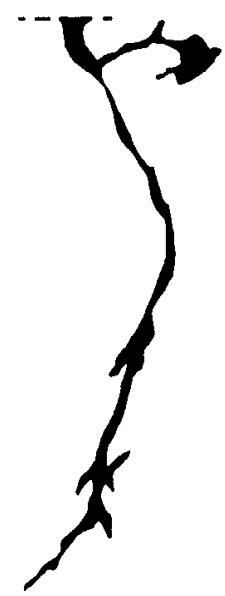

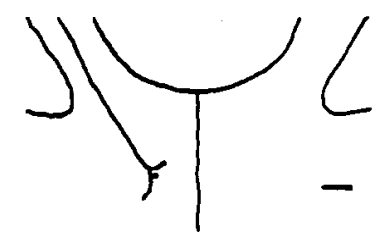

Figure 10. Growth cone turning at midline. This fiber was labeled in the inferior temporal retina at E15, and recorded $12 \mathrm{hr}$ later, with a $100 \times$ objective. The distal tip of this fiber bore three neurites, each ending in a growth cone. Although growth cone $b(33$ min) continually expanded and collapsed (asterisk at $0,75,136,139 \mathrm{~min}$ ), and growth cone $a$ advanced slightly $(139 \mathrm{~min}$, arrow), only growth cone $c$ made a turn, by means of a single filopodium establishing the new direction of growth (arrow, $63 \mathrm{~min}$ ). In addition, at $142 \mathrm{~min}$ the growth cone, having begun to turn, became asymmetric and again adjusted the new axis of growth with the right-hand portion of the growth cone. Adjustment of direction occurred again at $166 \mathrm{~min}$, with the left-hand filopodium becoming dominant. Note that the entire array of growth cones and parent neurite paused near the midline for 3 hours. Compare these images to Figure 6, $p$ and $q$, in Godement et al. (1990). Inset is as in Figure 7. Scale bars: long bar, $25 \mu \mathrm{m}$; short bar, $100 \mu \mathrm{m}$ for inset.

in Fig. $5 b$ ). Here, the majority of fibers made one to three extensive pauses for up to several hours. The pauses in the lateral chiasm were on the order of 15-30 min. Pause lengths in the midline region ranged from $30 \mathrm{~min}$ to $6 \mathrm{hr}$ (Table 1). After the long pauses in the midline region, fibers resumed growth, and either crossed the midline or turned back to the ipsilateral optic tract.

The pauses in growth seen at the midline lasted for several hours during the advance of both crossed and uncrossed fibers. In Figure 3, photographs of the actual frames from a sequence recorded at low power show that axon 1 paused for at least an hour before turning away from the midline, and axon 2, which ultimately crossed the midline also paused, here captured for about $6 \mathrm{hr}$. Axon 3 paused at least as long as axon 2, but its ultimate destination was unknown. Further, during the pause period displayed by axons 2 and 3, although the growth cones showed little net advance, the tips made small advances and retractions (about $10 \mu \mathrm{m}$ ) in the hour between frames $b$ and $d$ (Fig. 3).
Between these pauses, in both the lateral chiasm and in the midline region, growth cones extended at a rapid rate, from 60 to $80 \mu \mathrm{m} / \mathrm{hr}$, irrespective of the destination of the fiber. In the lateral chiasm, the rate of progression, summing the advance and pause periods, was faster $(\sim 50 \mu \mathrm{m} / \mathrm{hr})$ than in the midline region $(\sim 40 \mu \mathrm{m} / \mathrm{hr}$; Table 1$)$. The overall rate of progression in the whole chiasm was thus rather slow, given that the majority of fibers paused for long periods in the midline region. In contrast, the overall rate in paths where straight growth occurs, such as the optic tract, is nearly double that in the chiasm (Wang et al., 1993).

\section{Growth cone behavior in the chiasm}

A prominent feature of growth cone progression in the real-time recordings was the dynamic alteration in growth cone form (Figs. $3,6-10$ ). Lamellipodia and filopodia extended from the growth cone body, which was generally $10-25 \mu \mathrm{m}$ in length, as seen in fixed tissue. The time course of these shape changes was rapid, growth cones altering their form from squat and foliate to more 
Table 1. Kinetics of growth in the optic chiasm at E15-17

\begin{tabular}{|c|c|c|c|c|}
\hline & Number & $\begin{array}{l}\text { Average } \\
\text { pause } \\
\text { length } \\
\text { (min) }\end{array}$ & $\begin{array}{l}\text { Range } \\
\text { (min) }\end{array}$ & $\begin{array}{l}\text { Rate } \\
(\mu \mathrm{m} / \mathrm{hr})\end{array}$ \\
\hline \multicolumn{5}{|l|}{ Pauses } \\
\hline \multicolumn{5}{|c|}{ In midline region ( $200 \mu \mathrm{m}$ on either side of the midline) } \\
\hline Crossed axons & $9 / 10$ & 58 & $30-120$ & - \\
\hline Uncrossed axons & $8 / 9$ & 130 & $45-300$ & - \\
\hline Unknown destination & $16 / 16$ & 97 & $30-240$ & - \\
\hline $\begin{array}{l}\text { In lateral chiasm ( } 200 \\
\mu \mathrm{m} \text { lateral to midline } \\
\text { region), before or af- } \\
\text { ter crossing midline }\end{array}$ & $9 / 9$ & 25 & $15-75$ & - \\
\hline \multicolumn{5}{|c|}{ Rate of advance (all fibers) } \\
\hline $\begin{array}{l}\text { When extending } \\
\text { Overall rate }\end{array}$ & 23 & - & & $71.3 \pm 8.7$ \\
\hline Lateral chiasm & 9 & - & & $50.9 \pm 22.4$ \\
\hline Midline region & 19 & - & & $38.7 \pm 10.3$ \\
\hline
\end{tabular}

elongated in a matter of minutes (e.g., Fig. 8, 37-50 min). During extension, when growth cones had predominantly streamlined lamellipodial forms, the form changed every few minutes because of the extension of the forward parts of the growth cone, with expansion and slimming as the growth cone moved forward (Figs. 6-10).

A representative example of a growth cone cycling through a bout of advance, a pause in growth, and resumption of advance is shown in Figure 6, monitored after it crossed the midline but within the midline zone. This growth cone extended $30 \mu \mathrm{m}$ in $20 \mathrm{~min}$, all the while primarily maintaining an elongated lamellipodial shape. Subsequently, it paused for $34 \mathrm{~min}$, flattencd and spread, condensed, and flattened again. During the last expansion, the tip of the growth cone pointed in a slightly different axis. When rapid extension again resumed, the growth trajectory shifted to the new axis. The growth cone then extended an additional $25 \mu \mathrm{m}$ in $19 \mathrm{~min}$.

During the long pauses in the midline region and during crossing of the midline, fibers appeared to make small advances and retractions without net advance. An example of this is shown in Figure 7 in a fiber in the process of crossing the midline. In the $3.5 \mathrm{hr}$ it was monitored, it paused extensively. In addition, the form of the body of the growth cone changed shape, from tapered to more broad, and projected and withdrew filopodia (Fig. 7; compare arrowhead at $60 \mathrm{~min}$, to $81 \mathrm{~min}$ ). The shape of the growth cone changed considerably during the pause periods, for example, from 24 to $60 \mathrm{~min}$ and from 81 to $107 \mathrm{~min}$. However, during these morphogenetic changes, whilc the length of the growth cone (distance from the neck of the growth cone to the tip) ranged from $10-30 \mu \mathrm{m}$, the position of the neck of the growth cone did not change (dashed line, Fig. 7). Finally, when filopodial extensions were asymmetric, for example, at $191 \mathrm{~min}$, a shift in the axis of growth was implemented.

Advance of the growth cone tip often occurred with the neck or the tip moving forward, but not both simultaneously. First, the tip advanced with the neck of the body of the growth cone stable, as in Figure 7, $98 \mathrm{~min}$ to $149 \mathrm{~min}$. Subsequently, the growth cone body foreshortened and the former neck and prox- imal growth cone became neurite, such that the tip and the growth cone moved forward compared to the position of these portions of the growth cone at $98 \mathrm{~min}$. Thus, the growth cone could advance by undergoing cycles of "bringing up the rear" of the growth cone forward.

In summary, the general kinetics of retinal axons in the chiasm had the following features: (1) retinal fibers displayed saltatory growth in the chiasm; (2) during a pause, growth cones were active, constantly extending and retracting appendages and portions of the body of the growth cone; (3) despite the motile activity, changes in shape, and short-distance ranging of the growth cone tip, there was no net extension of the neurite during a pause; (4) asymmetric extensions projections of the growth cone preceded a shift in the direction of growth.

\section{Morphogenesis of growth cones during turning away from the midline}

In the midline region, growth cones on axons labeled in the inferior temporal retina were studied at low and high magnification to document the changes in growth cone morphology during pausing and subsequent turning away from $(n=9)$ or crossing $(n=5)$ the midline. Growth cones of axons that ultimately turned or crossed the midline were tapered as they advanced, and spread and complex during a pause, irrespective of subsequent crossing (e.g., Fig. 7) or turning away from (e.g., Fig. 8 ) the midline. All growth cones repeatedly developed tapered and more spread forms. However, only growth cones from inferior temporal retina displayed dramatic shape changes, generally just prior to the actual turn. Such growth cones developed T-shaped configurations (Fig. 9) and even multiple foci of motile growth cone-like activity oriented in different axes (Fig. 10). These more extreme morphogenetic changes were never seen in axons that crossed the midline (Fig. 7).

Figure 8 shows an example of the behavior and corresponding morphogenetic changes of a turning growth cone at high magnification. During a first stage lasting about $65 \mathrm{~min}$, the growth cone extended forward, then retracted slightly as it developed several lateral processes and spread, and then reextended at the forward tip. This cycle was repeated several times. Subsequently, the body of the growth cone thinned and a "backward" filopodium formed along the growth cone at $65 \mathrm{~min}$ (arrow, Fig. 8). Finally, at the tip of the filopodium, a new growth cone developed and extended rapidly back toward the ipsilateral optic tract. As this occurred, the remnant of the branched growth cone tip that had extended toward the midline disappeared (Fig. 8 ; compare 65 and $81 \mathrm{~min}$ to $91 \mathrm{~min}$ ).

Five other monitored growth cones displayed similar sequences of development of highly complex growth cones proximal to the midline, including repeated protrusion and withdrawal, as well as slimming and expansion, of processes and portions of the growth cones distal to the neck of the growth conc, all the while displaying no real advance during these morphogenetic alterations within the midline zone. In Figure 9, a single growth cone split into three parts at $12 \mathrm{~min}$, two parts at $27 \mathrm{~min}$, and again into three parts at $33 \mathrm{~min}$. A single filopodium developed at the left branch at $42 \mathrm{~min}$. Different parts of the " $T$ " were more prominent than others at ensuing times until $63 \mathrm{~min}$. Ultimately the branch of the $\mathrm{T}$ from which the single filopodium developed at 42 min slimmed and developed a tapered growth cone that rapidly extended in the new direction of growth.

A remarkable set of morphogenetic transformations occurred 
in the growth cone in Figure 10. A T formation developed as in the growth cone in Figure 9, but the end of the neurite bore three distinct neuritic branches, each bearing a growth cone. The growth cone at the top of the array (a) was active in that it repeatedly changed shape, remodeled, then shriveled. The middle growth cone (b) then showed a similar cycle of changes, followed by remodeling of the third growth cone (c), which ultimately effected the turn. In all three turning fibers depicted here (Figs. 8-10), the remnants of the withdrawn portions or subdivided growth cones were represented by stubs after the turn was made.

Other turning growth cones were observed at lower power (e.g., Fig. 3) on axons labeled in the inferior temporal retina ( $n$ $=4$ ) and while their detailed morphology could not be analyzed, it was evident that turning away from the midline was preceded by a pause in their advance of several hours, during which the growth cones assumed morphologies that were considerably more spread and complex than the forms seen on crossing growth cones during pausing at the midline. Following remodeling of selective portions of the growth cone or of the often multiple growth cones on a single neurite, the fiber rapidly advanced in a new direction, a direction dictated by a single backward filopodium.

\section{Discussion}

The present real-time views of divergence of retinal axons in the optic chiasm directly demonstrate fiber itineraries, the tempo of growth, and growth cone behaviors, all features impossible to determine in fixed static preparations. In addition, the realtime sequences further illuminate the location of cues for axon navigation and the response of growth cones to the putative cues, in this particular decision region. First, the advance of retinal fiber growth cones in the optic chiasm is interrupted by long pauses. Second, these pauses are most prominent within a zone adjacent to the midline of the optic chiasm, supporting the hypothesis raised in our previous study (Godement et al., 1990) and more recently by Sretavan and Reichardt (1993) that the chiasm midline contains cues for retinal fiber divergence. Third, during the pauses in extension, growth cones advance and retract the full length of their tip and remain motile, thereby remodeling their form continuously, but without any net extension. Fourth, during these phases of remodeling, a change in growth direction is always preceded by asymmetries in the extension of growth cone appendages. Finally, the turns made by uncrossed fibers in the midline region of the optic chiasm involve a particularly striking instance of remodeling of their terminal ends - the pruning of processes located near the midline coupled with the elaboration of a single process that heralds the new direction of growth away from the optic chiasm midline.

These experiments also show that growth cone behavior can be directly visualized in real time in semiintact embryonic mammalian brain, in agreement with other recent documentation by video microscopy of axonal growth cone behavior in the intact or semi-intact nervous system of invertebrates and lower vertebrates (Harris et al., 1987; O'Connor et al., 1990; O'Rourke and Fraser, 1990; Kaethner and Stuermer, 1992) and in mammals (Sretavan and Reichardt, 1993; Dailey et al., 1994; Halloran and Kalil, 1994), and the real-time accounts of the behavior of migrating and premigratory neurons (Komuro and Rakic, 1992; O'Rourke et al., 1992; Fishell et al., 1993). Moreover, many of the early steps in the growth of retinal fibers documented or deduced from intact brain by other neuroanatomical means occur in living slices of tissue.

\section{Development of the retinal pathway in the slice preparations}

On a macroscopic level, the present real-time analysis shows that crossed and uncrossed fibers diverge near the midline of the chiasm beginning at approximately E15. During this period, fibers from nasal retina as well as dorsal temporal retina were observed to cross the midline. In contrast, a large proportion of fibers from the inferior temporal retina were observed to approach the midline but turn away from it, back to the ipsilateral optic tract. On a microscopic level, in both the time lapse observations and in the fixed DiI-labeled preparations, widespread bifurcated growth cones have been seen only on fibers labeled in the inferior temporal retina. The real-time accounts show that fibers with such terminal endings eventually turn ipsilaterally. Therefore, the process of divergence of crossed and uncrossed fibers can be analyzed in these slice preparations.

Other studies on the growth of retinal axons in the chiasm using a similar preparation and video time-lapse technology (Sretavan and Reichardt, 1993) have shown that turning of ipsilateral fibers occurred near the midline, but that growth in the midline region was rapid, without pauses and without the extensive remodeling of growth cone morphology reported here. The different conclusions drawn by their study compared to the present one are most likely due, first, to the age of the preparation used, as observations were made at E13-E14, rather than E15E16 (see Fig. 1), as in the present study. An additional contrast between the two studies is that whereas the present real-time observations were made in normal preparations, Sretavan and Reichardt (1993) analyzed preparations in which one eye was removed at E11.5, in an effort to test the role of fiber-fiber interactions. Despite the apparent differences, however, both studies point to distinct responses on the part of crossed and uncrossed retinal axons at the midline during divergence to both sides of the brain.

\section{Growth cone kinetics: pauses in advance within a decision region}

Observing growth cone maneuvers in their natural environment has yielded novel information on general aspects of growth cone kinetics. All fibers whose growth was monitored in the present study displayed saltatory growth, or cycles of advance and rests. The rate of growth of retinal fibers $(60-100 \mu \mathrm{m} / \mathrm{hr}$ during advance) is comparable to the speed of axonal growth cones (e.g., Baird et al., 1992), growing astroglial processes (Mason et al., 1988), and migrating neurons (Edmondson and Hatten, 1987) in vitro. A similar rate of growth was predicted by Colello and Guillery (1992) in an EM analysis of position of growth cones in the mouse optic nerve, and is within the range of rates documented in real-time studies of retinal axon growth in the optic tract of Xenopus (Harris et al., 1987) and in the mouse chiasm (Sretavan and Reichardt, 1993).

While a stop-start pattern of advance may be common to motile cells (Abercrombie and Heaysman, 1953; Edmondson and Hatten, 1987), one difference in the pattern of growth of retinal fibers in the chiasm was the extended pause period seen in retinal fibers, up to several hours, compared to the several minute pauses displayed by migrating neurons in vitro (Edmondson and Hatten, 1987) and in vivo (Komuro and Rakic, 1992). The long pause periods, the most novel feature of the cadence of growth observed in this study, occur prior to drastic 
changes in progression and directionality within the chiasm, and may be intrinsic to the navigation process in decision regions. In agreement with this hypothesis, retinal fibers pause for much shorter periods during extension in the optic tract (Harris et al., 1987; Wang et al., 1993). Further evidence comes from documentation of the growth of sensorimotor axons across the corpus callosum, where pauses in growth are two to four times longer (up to $45 \mathrm{~min}$ ) at the entrance to subcortical areas than they are in the callosum or within the target layers of the cortex itself (Halloran and Kalil, 1994).

The observation that both uncrossed and crossed growth cones pause at the midline, involving the extension-retraction behavior of individual growth cones without any net advance, reinforces the notion that this zone contains cues for axon guidance during retinal axon divergence. Other studies from our laboratory have indicated that the zone flanking the midline in which growth cones display long pauses contains specialized radial glia (Mason et al., 1991, unpublished observations). Moreover, retinal axons display differential degrees of growth on chiasm membranes (Wizenmann et al., 1993) or dissociated cells (Wang et al., 1992; Marcus, Blazeski, Godement, and Mason, unpublished observations) from the midline region of the chiasm. The cellular and molecular components within this zone may thus instigate the pauses in growth of both crossed and uncrossed fibers and as such may constitute a more complex region than the lateral chiasm. The presence of cues at the chiasm midline directing divergence fits with a large number of studies demonstrating a role for the midline of the CNS in axon guidance, where axon populations cross (Dodd et al., 1988; Klambt et al., 1991; Yaginuma et al., 1991; Bernhardt et al., 1992), or are prevented from crossing (Snow et al., 1991; Wu et al., 1991), the neuraxis. It should be emphasized that at this site in the chiasm, axons from a single source are both permitted and barred from crossing the midline.

\section{Growth cone kinetics: the relationship of growth cone behavior and form}

In the semiintact slab preparations used here, the growth cones extending in an environment that nearly matches conditions in vivo. The power of this approach is that the growth cone forms observed in fixed preparations can now be directly matched to the forms observed in real time, and related to behaviors that had been formerly identified in vitro. In addition, the real-time sequences elucidate the function of different appendages of the growth cone and the sequence in which the different forms appear.

A large number of studies have demonstrated in fixed dyelabeled preparations that simple streamlined growth cones are seen in straight paths and complex spread forms bearing filopodia are seen in decision regions (e.g., Tosney and Landmesser, 1985; Caudy and Bentley, 1986; Bovolenta and Mason, 1987; Nordlander, 1987; Holt, 1989; Norris and Kalil, 1990; Bovolenta and Dodd, 1991; Kim et al., 1991; Yaginuma et al., 1991; Wang et al., 1993). In the present study, we correlated form with behavior, within the single locale of the chiasm, and observed that the simple forms were common during advance and the complex forms during a pause in growth, in agreement with two other recent studies using video time-lapse imaging (Kaethner and Stuermer, 1992; Halloran and Kalil, 1994). Both forms are commonly seen in the chiasm in real time accounts, but because pauses are more extended in the chiasm, the complex forms appear to predominate when growth cone form is analyzed in fixed tissue (e.g., Bovolenta and Mason, 1987).
The extreme case of course correction represented by the sharp turns made by uncrossed axons in the midline is not mediated by the straightforward extension of appendages on the growth cone, but by a highly asymmetric remodeling of the body of the growth cone, termed "micropruning" by Burmeister and Goldberg (1988). Our real-time observations of fibers that are branched and tipped with several growth-cone like structures suggest that one form of response of growing fibers in avoiding select environments in pathways or in temporary targets involves large-scale transformations of their terminal ends. Recent studies of the morphologies of retinal fibers in the embryonic rat superior colliculus and of their behavior in response to superior colliculus membranes also support this notion (Simon and O'Leary, 1992).

The abrupt shifts in the axis of growth heralded by the biased retention of lamellipodia or filopodia have been seen both in vivo (O'Connor and Bentley, 1990; Kaethner and Stuermer, 1992) and in vitro (Oakley and Tosney, 1993). The steps in turning at the chiasm midline are also reminiscent of the sequence of growth cone morphogenesis in neurons in the insect limb bud. After the growth cone spreads along a segment boundary that does not support extension, a single filopodium, subsequent to contacting a guidepost cell, establishes the new growth axis from which extension proceeds (Sabry et al., 1991). While filopodia are not as predominant on the retinal growth cones as they are in many growth cones in tissue culture, their role in growth cone stccring, especially the backward filopodia projectcd just beforc a turn, appears to be critical (see Chien et al., 1993).

In vitro studies have elucidated the behavioral responses of growth cones as they contact other cells. In the reaction considered to be most negative, the entire growth cone "collapses" as it contacts other fibers or cells (Kapfhammer and Raper, 1987; Bandtlow et al., 1990; Moorman and Hume, 1990) or in response to secreted or membrane-bound inhibitory molecules (Cox et al., 1990; Davies et al., 1990; Raper and Kapfhammer, 1990). In our study, we never observed a complete collapse and withdrawal episode of the entire growth cone. Some aspects of the behavior of retinal growth cones at the midline are, however, reminiscent of the collapse phenomenon in response to inhibitory cues, namely the repeated cycles of slimming and expanding during a pause, either of a single growth cone or of several growth cone-like expansions, followed by the shrinking, or micropruning, of sclect processes.

\section{A model for growth cone navigation in decision regions}

Interactions that lead to divergence of crossed and uncrossed fibers and other rearrangements of retinal fiber trajectories in the optic chiasm, as in other models of axon guidance, are likely to be complex and involve multiple cues (see Tosney, 1991; Chitnis and Kuwada, 1990). Our observations of axon navigation in a decision region therefore do not easily relate to the purely inhibitory, adhesive, or nonadhesive types of interactions that have been defined in simple tissue culture assays (e.g., Letourneau, 1975; Burmeister and Goldberg, 1988; Bandtlow et al., 1990; Cox et al, 1990), although these approaches provide working models for axon navigation in the intact nervous system.

The tempo and cadence of axon growth through the chiasm, as observed in the present study, suggest a model for axon extension and motility in the intact nervous system (Fig. 11). The rate, and perhaps the duration, of advance would be similar irrespective of the environment in which the growth cone was extending - straight paths or decision regions. In contrast, pause 


\section{GROWTH CONE MOTILITY IN VIVO}

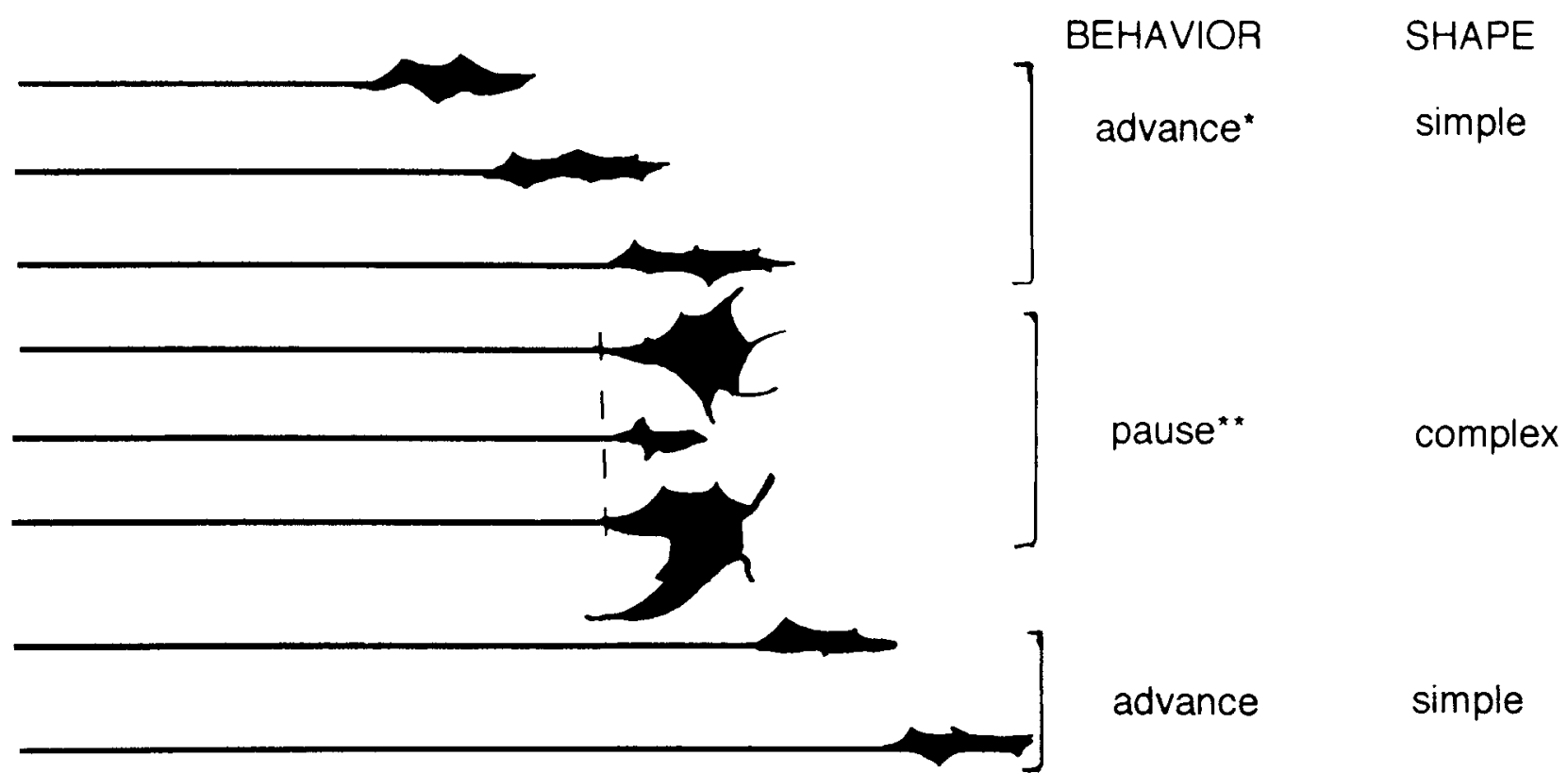

* duration, rate fixed

${ }^{* *}$ duration varies with locale, and growth axis

Figure 11. Model of growth cone extension: relationship of growth cone shape changes and kinetics. Within the optic chiasm, all growth cones undergo episodes of rapid advance and pauses. During advance, the rate, and perhaps duration, of extension would be similar. During pauses, growth cones make small retractions and advances, and spread and condense, but there is no net advance in the extension of the fiber (dashed line marks neck of the growth cone). Pause length is varied, depending on whether the axis of growth changes, with longer pauses preceding more drastic alterations in direction. Growth cone form constantly changes during advance and pauses. Even within one particular locale such as the optic chiasm (see Bovolenta and Mason, 1987), growth cones display predominantly streamlined forms during rapid advance, and more complex forms during pauses. During pauses preceding a slight shift in direction, growth cones develop expanded bodies and filopodia. During the longer pauses in preparation for turning, growth cones branch, divide into multiple motile tips, and extend backward filopodia.

periods would be variable, of longer duration in decision regions, and more brief, if at all present, in areas where straightforward elongation takes place. The longest pauses would precede sharp changes in direction or entry into a locale more complex or different from the previous one, presumably where more complex cues are located, whereas shorter pauses would punctuate advances that maintain the same directionality or result in slight shifts in the trajectory. The small advances and retractions coupled with the development of complex growth cone forms during long pauses comprise "exploration," long postulated as a response to novel and directive cues in decision regions. This model is currently under investigation (Wang et al., 1993, unpublished observations).

\section{Conclusions}

We have observed the behavior and kinetics of retinal growth cones during their trajectory through the optic chiasm, a decision region where fibers diverge to each side of the brain. Retinal axons display saltatory growth throughout the chiasm, but pauses in growth are more extended at the midline. During these pauses, growth cones are motile and make small advances and retractions, with no net increase in advance. Fibers from dorsal temporal and nasal retina, source of crossed fibers, progress across the midline, while uncrossed fibers originating in inferior temporal retina spread their growth cones then rapidly turn back to the ipsilateral optic tract by selective extension and retraction of portions of the growing tip of the axon.

These studies point to inhibition of uncrossed fiber extension and permissive advance of crossed fibers at the chiasm midline as important components of the establishment of the binocular projection. A molecular system on midline cells, or molecular differences between the two subpopulations of retinal ganglion cells that would subserve binocular divergence has not been revealed to date. The documentaries of growth cone behavior in the semi-intact preparation described here provide an experimental system by which to test the mechanisms underlying 
retinal axon divergence and, in general, the navigation of growth cones through decision regions to targets.

\section{References}

Abercrombie M, Heaysman JE (1953) Observations on the social behavior of cells in tissue culture. I. Speed of movement of chick heart fibroblasts in relation to their mutual contacts. Exp Cell Res 5:111-131.

Baird DH, Hatten ME, Mason CA (1992) Cerebellar target neurons provide a stop signal for afferent neurite extension in vitro. J Neurosci 12:619-634.

Baker GE, Reese BE (1993) Chiasmatic course of temporal retinal axons in the developing ferret. J Comp Neurol 330:95-104.

Bandtlow C, Zachleder T, Schwab ME (1990) Oligodendrocytes arrest neurite growth by contact inhibition. J Neurosci 10:3837-3848.

Bernhardt RR, Nguyen N, Kuwada JY (1992) Growth cone guidance by floor plate cells in the spinal cord of zebrafish embryos. Neuron 8:869-882.

Bovolenta P, Dodd J (1990) Guidance of commissural growth cones at the floor plate in embryonic rat spinal cord. Development 109: 435-438.

Bovolenta P, Mason CA (1987) Growth cone morphology varies with position in the developing mouse visual pathway from retina to first targets. J Neurosci 7:1447-1460.

Burmeister DW, Goldberg DJ (1988) Micropruning: the mechanism of turning of Aplysia growth cones at substrate borders in vitro. J Neurosci 8:3151-3159.

Caudy M, Bentley D (1986) Pioneer growth cone morphologies reveal proximal increases in substrate affinity. J Neurosci 6:364-379.

Chien C, Rosenthal DE, Harria WA, Hold CE (1993) Navigational errors made by growth cones without flopodia in the embryonic Xenopus brain. Neuron 11:237-251.

Chitnis AB, Kuwada JY (1990) Axonogenesis in the brain of zebrafish embryos. J Neurosci 10:1892-1905.

Colello RJ, Guillery RW (1990) The early development of retinal ganglion cells with uncrossed axons in the mouse: retinal position and axon course. Development 108:515-523.

Colello RJ, Guillery RW (1992) Observations on the early development of the optic nerve and tract of the mouse. J Comp Neurol 317: $357-378$.

Cooper MW, Smith SJ (1992) A real-time analysis of growth conetarget cell interactions during the formation of stable contacts between hippocampal neurons in culture. J Neurobiol 23:814-828.

Cornel E, Holt C (1992) Precocious pathfinding: retinal axons can navigate in an axonless brain. Neuron 9:1001-1011.

Cox EC, Muller B, Bonhoeffer F (1990) Axonal guidance in the chick visual system: posterior tectal membranes induce collapse of growth cones from temporal retina. Neuron 4:31-37.

Dailey ME, Buchanan J, Bergles DE, Smith SJ (1994) Mossy fiber growth and synaptogenesis in rat hippocampal slices in vitro. J Neurosci 14:1060-1078.

Davies JA, Cook GMW, Stern CD, Keynes RJ (1990) Isolation from chick somites of a glycoprotein fraction that cause collapse of dorsal root ganglion growth cone. Neuron 4:11-20.

Dodd J, Morton SB, Karagogeos D, Yamamoto M, Jessell TM (1988) Spatial regulation of axonal glycoprotein expression on subsets of embryonic spinal neurons. Neuron 1:105-116.

Dräger UC (1985) Birth dates of retinal ganglion cells giving rise to the crossed and uncrossed optic projections in the mouse. Proc R Soc Lond [Biol] 224:57-77.

Edmondson JC, Hatten ME (1987) Glial-guided granule neuron migration in vitro: a high-resolution time-lapse video microscopic study. J Neurosci 7:1928-1934.

Fishell G, Mason CA, Hatten ME (1993) Dispersion of neural progenitors within the germinal zone of the forebrain. Nature 362:636638.

Garriga G, Desai C, Horvitz HH (1993) Cell interactions control the direction of outgrowth, branching and fasciculation of the HSN axons of Caenorhabditis elegans. Development 117:1071-1087.

Godement P, Salaün J, Métin C (1987a) Fate of uncrossed retinal projections following early or late prenatal monocular enucleation in the mouse. J Comp Neurol 255:97-109.

Godement P, Vanselow J, Thanos S, Bonhoeffer F (1987b) A study in developing visual systems with a new method of staining neurones and their processes in fixed tissue. Development 101:697-713.

Godement P, Salaün J, Mason CA (1990) Retinal axon pathfinding in the optic chiasm: divergence of crossed and uncrossed fibers. Neuron 5:173-196.

Guillery RW (1982) The optic chiasm of the vertebrate brain. Contrib Sensory Physiol 7:39-73.

Halloran MC, Kalil K (1994) Dynamic behaviors of growth cones extending in the corpus callosum of living cortical brain slices observed with video microscopy. $J$ Neurosci, in press.

Harris WA (1989) Local positional cues in the neuroepithelium guide retinal axons in the embryonic Xenopus brain. Nature 320:266-269.

Harris WA, Holt CE, Bonhoeffer $F$ (1987) Retinal axons with and without their somata, growing to and arborizing in the tectum of frog embryos: a time-lapse video study of single fibers in vivo. Development 101:23-133.

Hatten ME, Francois AM (1981) Cell assembly patterns of embryonic and early postnatal mouse cerebellar cells on lectin-derivatized culture substrata. Dev Biol 87:102-113.

Holt CE (1989) A single-cell analysis of early retinal ganglion cell differentiation in Xenopus: from soma to axon tip. J Neurosci 9:31233145 .

Kaethner RJ, Stuermer CAO (1992) Dynamics of terminal arbor formation and target approach of retinotectal axons in living zcbrafish embryos. A time lapse study of single axons. J Neurosci 12:32573271 .

Kapfhammer J, Raper J (1987) Collapse of growth cone structure on contact with specific neurites in culture. $\mathbf{J}$ Neurosci 7:201-212.

Kim GJ, Shatz CJ, McConnell SK (1991) Morphology of pioneer and follower growth cones in the developing cerebral cortex. J Neurobiol 22:629.

Klambt C, Jacobs JR, Goodman CS (1991) The midline of the Drosophila central nervous system: a model for the genetic analysis of cell fate, cell migration, and growth cone guidance. Cell 64:801-815.

Komuro H, Rakic P (1992) Selective role of N-type calcium channels in neuronal migration. Science 257:806-809.

Kuwada JY, Bernhardt RR, Chitnis AB (1990) Pathfinding by identificd growth concs in the spinal cord of zcbrafish embryos. J Neurosci 10:1299-1308.

Letourneau $P$ (1975) Cell-to-substratum adhesion and guidance of axonal elongation. Dev Biol 44:92-101.

Mason CA, Edmondson JC, Hatten ME (1988) The extending astroglial process: development of glial cell shape, the growing tip, and interactions with neurons. I Neurosci 8:3124-3134.

Mason CA, Dodd J, Blazeski R, Godement P (1991) The midline of the mouse optic chiasm: cellular composition and antigen expression during retinal axon growth. Soc Neurosci Abstr 17:39.

Moorman SJ, Hume RI (1990) Growth cones of chick sympathetic preganglionic neurons in vitro interact with other neurons in a cellspecific manner. J Neurosci 10:3158-3163.

Nordlander RH (1987) Axonal growth cones in the developing amphibian spinal cord. J Comp Neurol 263:485-496.

Norris CR, Kalil K (1990) Morphology and cellular interactions of growth cones in the developing corpus callosum. J Comp Neurol 293: 268-281.

Oakley RA, Tosney KW (1993) Contact-mediated mechanisms of motor axon segmentation. J Neurosci 13:3773-3792.

O'Connor TP, Duerr JS, Bentley D (1990) Pioneer growth cone steering decisions mediated by single filopodial contacts in situ. J Neurosci 10:3935-3946.

O'Rourke NA, Fraser SE (1990) Dynamic changes in optic fiber terminal arbors lead to retinotopic map formation: an in vivo confocal microscopic study. Neuron 5:159-171.

O'Rourke N, Dailey M, Smith S, McConnell S (1992) Diverse migratory pathways in the developing cerebral cortex. Science 258:299302.

Polyak SL (1957) The vertebrate visual system. Chicago: University of Chicago.

Raper JA, Kapfhammer JP (1990) The enrichment of a neuronal growth cone collapsing activity from embryonic chick brain. Neuron 4:21-29.

Reese B, Guillery RW, Marzi CA, Tassinari G (1991) Position of axons in the cat's optic tract in relation to their retinal origin and chiasmatic pathway. I Comp Neurol 306:539-553. 
Roberts A, Taylor J (1983) A study of the growth cones of developing embryonic sensory neurites. J Embryol Exp Morphol 75:31-47.

Sabry JH, O'Connor TP, Evans L, Toroian-Raymond A, Kirschner M, Bentley D (1991) Microtubule behavior during guidance of pioneer neuron growth cones in situ. J Cell Biol 115:381-395.

Shatz CJ, Sretavan DW (1986) Interactions between retinal ganglion cells during the development of the mammalian visual system. Annu Rev Neurosci 9:171-207.

Simon DK, O'Leary DD (1992) Responses of retinal axons in vivo and in vitro to position-encoding molecules in the embryonic superior colliculus. Neuron 9:977-989.

Snow DM, Steindler DA, Silver J (1991) Molecular and cellular characterization of the glial roof plate of the spinal cord and optic tectum: a possible role for a proteoglycan in the development of an axon barrier. Dev Biol 138:359-376.

Sretavan DW (1990) Specific routing of retinal ganglion cell axons at the mammalian optic chiasm during embryonic development. J Neurosci 10:1995-2007.

Sretavan DW, Reichardt LF (1993) Time-lapse video analysis of retinal ganglion cell axon pathfinding at the mammalian optic chiasm: growth cone guidance using intrinsic chiasm cues. Neuron 10:761777 .
Tosney KW (1991) Growth cone navigation in the proximal environment of the chick embryo. In: The nerve growth cone (Kater S, Letourneau P, Macagno E, eds), pp 387-403. New York: Raven.

Tosney KW, Landmesser LT (1985) Growth cone morphology and trajectory in the lumbosacral region of the chick embryo. J Neurosci 5:2345-2358.

Wang L-C, Godement P, Mason CA (1992) Cells of the optic chiasm midline inhibit uncrossed retinal fiber outgrowth in vitro. Soc Neurosci Abstr 18:222.

Wang L-C, Godement P, Mason CA (1993) Growth cone form is behavior-and position-specific. Soc Neurosci Abstr 19:620.

Wizenmann A, Thanos S, Boxberg YV, Bonhoeffer F (1993) Differential reaction of crossing and non-crossing rat retinal axons on cell membrane preparations from the chiasm midline: an in vitro study. Development 117:725-735.

Wu D-Y, Silver J, Schneider GE, Jhaveri S (1991) The barrier function of tectal midline glial cells and its association with proteoglycan distribution. Soc Neurosci Abstr 17:741.

Yaginuma H, Shunsaku H, Kunzi R, Oppenheim RW (1991) Pathfinding by growth cones of commissural interneurons in the chick embryo spinal cord; a light and electron microscopic study. J Comp Neurol 304:78-102. 